\title{
I. PRESENTACIÓN DE LA TERCERA EDICIÓN DEL LIBRO: "GARANTIAS CONSTITUCIONALES DEL PROCESO" DEL DR. JOSÉ OVALLE FAVELA.
}

\author{
Presentadora: Dra. Adria GONZALEZ BELTRONES \\ Jueves 21 de Agosto de 2008 18:00 horas \\ Aula Magna Roberto Reynoso Dávila \\ División de Ciencias Sociales \\ Unidad Regional Centro \\ Departamento de Derecho \\ Universidad de Sonora
}

En nuestro país hay, varias formas de presentar un libro. Algunas resultan amenas y tediosas, mientras que otras, sólo tediosas, y alguna que otra, sólo amena. De todo corazón, deseo que este acto de presentación del libro "Garantías Constitucionales del Proceso", en su tercera edición, del reconocido Jurisconsulto Dr., José Ovalle Favela -quien esta tarde nos acompaña y con ello se engalana el ciclo escolar 2008-2 que formalmente se inició esta semana en nuestro Departamento de Derecho- resulte una presentación amena, pero más allá de ello, desearía entusiastamente que cada uno de los asistentes a este acto se sume al gremio de los que además de amar el arte de escribir, admiramos la más importante de las artes que amerita el autor de un libro: el de ser lector. Pues bien en esta tercera edición de Garantías Constitucionales del Proceso" nuestro autor realiza varios cambios importantes respecto a las dos ediciones anteriores cuya esencia se describe magistralmente en la Presentación y Carta-Prólogo de las primeras ediciones, de Don Luís de la Barreda Solórzano y Don Manuel Gutiérrez de Velasco respectivamente, ${ }^{1}$ así los presentadores en comento resaltan la calidad de nuestro autor como jurista reflexivo y crítico al examinar las garantías consagradas en los artículos 13,14,16 y 17 de nuestra Constitución con el rigor y profundidad de que le han dotado sus años de profesor e investigador universitario y su práctica de abogado de instituciones públicas y particulares. Por ello su examen no se detiene en los textos de las normas y en la doctrina correspondientes sino que abarca también la jurisprudencia, sustentando cada comentario en su consistente calidad académica y profesional. De los primeros capítulos de la versión prima de la obra en comento retomo el del artículo 14 pues coincido con nuestro erudito Doctor Ovalle en considerarlo uno de los pilares sobre los que descansa nuestro ordenamiento jurídico, pues de todos es sabido que en él se contienen cuatro de las más importantes garantías de seguridad jurídica: la de irretroactividad de la ley, la de audiencia, la de legalidad penal y la de legalidad civil. Al efecto y por abreviar mi intervención, solo resalto de este capítulo la forma tan amena en el que nuestro autor nos relata la apasionante polémica de fines de siglo XIX en la que por un lado José María Lozano e Ignacio L. Vallarta sostenían que la garantía establecida en el artículo 14 de la constitución de 1857 sólo era exigible en el ámbito penal: en tanto que por el otro, Miguel Mejía los refutaba con el argumento de que las expresiones juzgado y sentenciado, que utilizaba el texto constitucional, eran empleadas tanto en materia penal como en materia civil. Los amparos contra las resoluciones judiciales por "inexacta aplicación de la ley" se incrementaron en forma desmedida, por lo que considerando que tal situación hacía imposible la tarea de la Corte, movió a Rabasa a proponer una reforma sustancial al artículo 14 lo cual tuvo eco en el Congreso Constituyente de 1917 al limitarse la garantía de aplicación exacta de la ley al ámbito penal. En relación a la irretroactividad de la ley, la garantía de audiencia y el análisis de la legalidad penal y la legalidad civil, conmino a nuestra audiencia a deleitarse con la espléndida exposición de los principios generales del derecho y el repaso de la doctrina clásica y actual

En este tenor y en relación a la tercera edición en comento el Doctor Ovalle Favela enriquece la obra de orden procesal constitucional al agregar en primer término dos capítulos el 5 y el 6 . En el

\footnotetext{
${ }^{1}$ Quienes a la sazón fungen el primero de ellos como Director General del Instituto Ciudadano de Estudios sobre la inseguridad en tanto que el segundo como Ex Ministro de la Suprema Corte de Justicia de la Nación recientemente falleciera(10 de abril de 2007) Revista Jurídica del Departamento de Derecho Academia de Derecho Administrativo Tercera Época. Año 2. No 2. Vol. 1.Enero-Junio 2010
} 
capítulo 5 nuestro autor amplía el examen de las garantías constitucionales del proceso en nuestro país para incluir las que reconoce el artículo 19 de nuestra Carta Magna. Así mismo, en el capítulo 6 nos presenta un estudio de la evolución de las garantías fundamentales del proceso civil en el derecho comparado y en Iberoamérica, proponiendo además un proyecto de bases constitucionales para nuestra Región. Por último cabe señalar que como todo buen autor de obras jurídicas en las que el devenir histórico obliga a la actualización constante por la no inmutabilidad del quehacer humano, en los primeros cuatro capítulos realiza una excelente actualización de las tesis de jurisprudencia y los precedentes en ellos citados hasta diciembre de 2006. Asimismo en cada uno de los capítulos de la obra en comento se recogen las principales orientaciones de la jurisprudencia y se citan las fuentes de las tesis que se mencionan,, recogiéndose los principales cambios registrados en la jurisprudencia entre 2002 y 2006, de los cuales cabe destacar que si bien a partir de la quinta época la jurisprudencia había considerado que para que la autoridad administrativa ejerciera la facultad de expropiación por causa de utilidad pública, no era necesario que otorgara al posible afectado la garantía de audiencia; desde el 25 de agosto de 2006, la Segunda Sala de la Suprema Corte de Justicia de la Nación modificó esa interpretación al sostener en la tesis de jurisprudencia 2a-.J.124/2006, que para ejercer esa facultad la autoridad si debe otorgar la garantía de audiencia al afectado, previamente a la emisión del decreto de expropiación.

En este mismo rubro, nuestro autor destaca que si bien la jurisprudencia del Pleno de la Suprema Corte de Justicia ha sostenido que las formalidades esenciales del procedimiento son la notificación del inicio del procedimiento, la oportunidad de ofrecer y aportar pruebas, la oportunidad de alegar y la emisión de la resolución que dirima las cuestiones debatidas (tesis P./J.47/95,Semanario Judicial de la federación y su Gaceta, novena época, t. II, diciembre de 1995,p 133). Algunos precedentes de manera expresa habían excluido la impugnación de estas formalidades. La Primera Sala ha iniciado un cambio fundamental en este tema al reconocer en la tesis aislada 1a. LXXVI/2005, que el principio de impugnación de las sentencias constituye una de las formalidades esenciales del procedimiento (Semanario Judicial de la Federación y su Gaceta, novena época, t. XXII, agosto de 2005,pp.299 y 300) resaltando atinadamente nuestro autor que en caso de que este criterio se sostenga y se convierta en tesis de jurisprudencia, se podría impugnar la inconstitucionalidad de aquellas leyes procesales que no prevean medios de impugnación ordinarios en contra de las sentencias definitivas, como es el caso del título especial de la justicia de paz del Código de Procedimientos Civiles para el Distrito Federal entre otros ordenamientos.

De otra parte nuestro autor, tomando en consideración la cantidad cada vez mayor de las fuentes de las tesis de jurisprudencia y los precedentes que se analizan en cada capítulo, para comodidad de los lectores los transcribe en un disco compacto que se acompaña en forma gratuita a cada ejemplar de la edición que comentamos. Y lo mas maravilloso que los lectores podemos además imprimir o guardar los documentos consultados.

Ciertamente los que disfrutamos con la lectura, creemos que la mejor manera de presentarla, es invitando al lector al temario que contiene. Pues conviene experimentar y no en cabeza ajena el viaje por los capítulos del libro, deteniéndose en los paisajes más atractivos, sorteando a veces los más complejos, pero regresando a ellos para su disfrute o suplicio. Pero que mejor oportunidad que tener a nuestro lado al Autor de una obra académica útil y disfrutable, quien segura estoy en forma por demás generosa querrá compartir con los aquí reunidos algunos de sus planteamientos o propuestas en relación a nuestro sistema jurídico. 